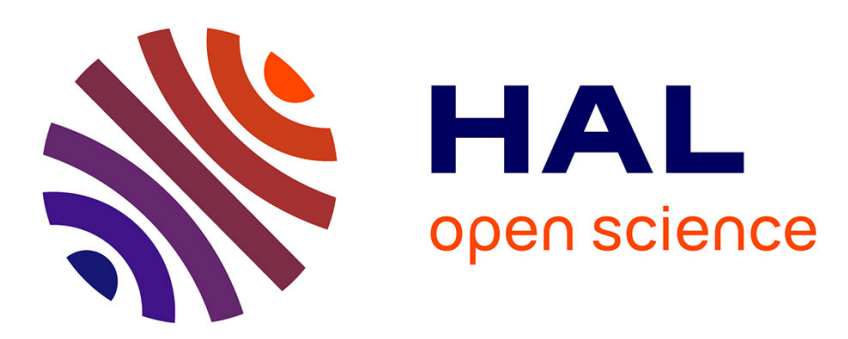

\title{
Using wide band signals for obstacle path correction in acoustic scintillation flow meters
}

Ion Candel, Cornel Ioana, David Lemon, Bertrand Reeb

\section{To cite this version:}

Ion Candel, Cornel Ioana, David Lemon, Bertrand Reeb. Using wide band signals for obstacle path correction in acoustic scintillation flow meters. ISSPA 2012 - 11th International Conference on Information Science, Signal Processing and their Applications, Jul 2012, Montréal, Canada. pp.180. hal-00985672

\section{HAL Id: hal-00985672 \\ https://hal.science/hal-00985672}

Submitted on 30 Apr 2014

HAL is a multi-disciplinary open access archive for the deposit and dissemination of scientific research documents, whether they are published or not. The documents may come from teaching and research institutions in France or abroad, or from public or private research centers.
L'archive ouverte pluridisciplinaire HAL, est destinée au dépôt et à la diffusion de documents scientifiques de niveau recherche, publiés ou non, émanant des établissements d'enseignement et de recherche français ou étrangers, des laboratoires publics ou privés. 


\title{
USING WIDE BAND SIGNALS FOR OBSTACLE PATH CORRECTION IN ACOUSTIC SCINTILLATION FLOW METERS
}

\author{
Ion CANDEL ${ }^{1,2}$, Cornel IOANA ${ }^{2}$, David LEMON ${ }^{3}$, Bertrand REEB ${ }^{1}$ \\ ${ }^{1}$ Electricité de France, Direction Technique Générale, Grenoble, France \\ ${ }^{2}$ Institute Polytechnique de Grenoble, GIPSA-Lab, Grenoble, France \\ ${ }^{3}$ ASL Environmental Sciences, Victoria, British Columbia, Canada \\ ion.candel@edf.fr, cornel.ioana@gipsa-lab.inpg.fr, dlemon@aslenv.com, bertrand.reeb@edf.fr
}

\begin{abstract}
This paper deals with the challenges of water flow measurement in hydroelectric plants using acoustic scintillation. One of the drawbacks of ultrasonic signal propagation through water is that measurements require relatively clean water conditions. In water with significant amount of impurities, the level of transmitted signals may not be sufficient for an accurate flow measurement. In terms of signal processing, the effect of impurities is represented by a random loss or fading of received signals. In order to improve the measurement, the wide band signals can be used in order to improve the quality factor of the signals by adaptive filtering using a static mode reference. Results show that, in real configurations, the interference due to the obstacles can be reduced.
\end{abstract}

Keywords: flow rate measurement, scintillation, CHIRP, wide band, matching filtering

\section{INTRODUCTION}

Acoustic scintillation flow metering promises to offer an elegant and efficient non-intrusive solution to flow metering by, in general: mounting the transducers on the outer walls of the pipe, transmitting a signal to be affected by the flow, and analyzing the received signal in order to obtain the flow parameters [1]. However, a series of tests in water containing impurities showed that the resulting insufficient signal levels may cause the system to stop the measurement.

\section{ACOUSTIC SCINTILLATION DRIFT}

The acoustic scintillation drift technique measures the water flow velocity perpendicular to a number of acoustic paths established across an intake to a turbine [2].

Short ultrasound pulses are sent from the transmitting arrays, on one side, to the receiving arrays on the other, at a rate of approximately 250pulses/second [3]. Turbulence embedded in the flow causes amplitude fluctuations in the acoustic signals (Fig. 1).

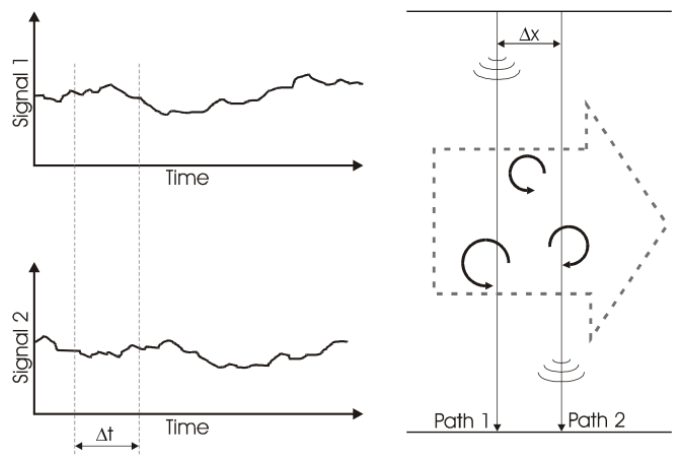

Figure 1.Diagram of the acoustic scintillation principle.

If the two paths are sufficiently close $(\Delta x)$, the turbulence effect on the signals remains virtually the same, except for a time delay, $\Delta t$. This time delay corresponds to the peak in the time-lagged cross-correlation function calculated for Signal $_{1}$ and Signal 2 . The mean velocity perpendicular to the acoustic paths becomes $v_{\text {mean }}=\Delta x / \Delta t$.

\section{USING LARGE BAND SIGNALS ON SCINTILLATION}

Amplitude variations found at the receiving end of the scintillation acoustic path can be calculated using a different technique, based on wide band signals, such as linear frequency modulations or CHIRPs.

Instead of using a pulse package of a single carrier frequency, the frequency within the burst is changed (swept) throughout the duration of the transmission, from one frequency to another [4]. In our application, we have constructed a wide band signal in order to replace the impulse package found in the emission stage. A matched filter is obtained by correlating a known signal, or reference, with an unknown signal to detect the presence of the reference in the unknown signal. This is equivalent to convolving the unknown signal with a conjugated time-reversed version of the template. 
Due to the high spectral content of a large band signal, the autocorrelation between two large band signals will always have a significant maximum for the main lobe.

Considering a CHIRP signal received when an obstacle blocks the acoustic path, the spectral content of the transmitted signal is still found when performing a time frequency analysis. Figure 2 illustrates the spectrogram for a received chirp signal in the case of an obstacle:
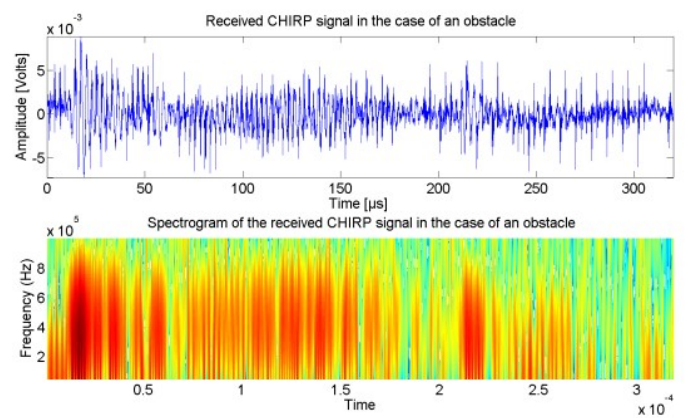

Figure 2. Spectrogram of a received CHIRP signal in the case of an obstacle.

For the same measurement, it is possible to view also the spectral content of a CHIRP signal received with no obstacle blocking the acoustic path, as shown in figure 3 .
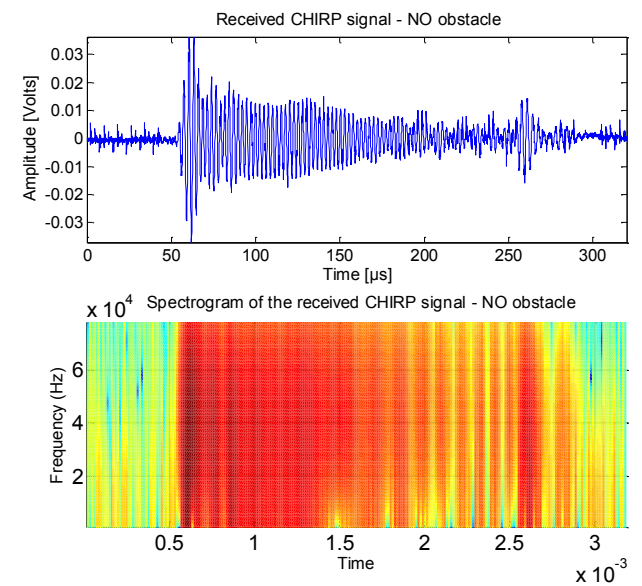

Figure 3. Spectrogram of a received CHIRP signal for no obstacle.

Using this property, we select a reference signal which will be the first term of the correlation. This reference is the received CHIRP signal which has traveled along the acoustic path during a clear water test. Next, we conduct an obstacle test that attenuates the acoustic path. For each received pulse we then calculate the corresponding correlation and extracted a maximum from each one. The extraction of maximums of correlations provides a new time series, which can be compared with the one based on envelope detection.

Figure 4 shows the difference between the time series calculated using the correlation and envelope detection: the influence due to the impurities/obstacles presented in the acoustic path is greatly reduced.

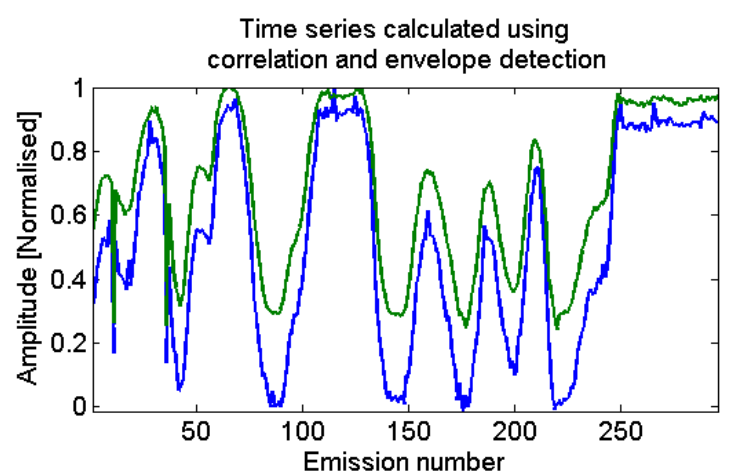

Figure 4. Time series computed using the correlation (green) and envelope detection (blue).

The two time - frequency representations in figures 2 and 3 show the potential of wide band signals in dealing with impurities/obstacles encountered across the acoustic path. It should be noted that these tests were carried out using signals with low levels of power, hence the low signal to noise ratio for the signal in figure 2 .

Another advantage of using large band signals arises from the "personalized" spectrum content: the algorithm can be rendered robust to outside perturbation and the complexity of the equipment can be reduced.

\section{CONCLUSIONS}

This paper deals with an improvement of a flow rate measurement method in the context of impurities/obstacles, as impurities/obstacles inherent in the water flow pose a threat to the overall accuracy of the measurement results.

Signal processing techniques can eliminate this drawback by constructing a new type of transmitting signal and by using a new method to quantify the turbulence embedded in the water flow. The method employs wide-band signals (CHIRPS) and the matching filtering. Worst case scenario tests have shown encouraging improvements in time series amplitudes.

Future work will consist in adding impurities of different sizes in the water flow and quantifying their influence on the time series, as well as on the water flow measurement accuracy.

\section{REFERENCES}

[1] L. C. Lynnworth, "Ultrasonic Measurements for Process Control: Theory, Techniques, Applications", Academic Press, 1989.

[2] D.D. Lemon, D.R. Topham, and D. Billeness, "Improvements to the Accuracy of Discharge Measurements by Acoustic Scintillation resulting from Revisions to Data Processing Procedures”, IGHEM, Oct. 21 -23, 2010.

[3] ASL AQFlow, ASFM Operations Manual, Victoria, British Columbia, Canada, 1998.

[4] M.I. Skolnik, Introduction to radar systems, Artech House, 1986. 